\title{
Coeliac disease in the Rehovot-Ashdod region of Israel: incidence and ethnic distribution
}

\author{
S DAHAN, ${ }^{1}$ P E SLATER, ${ }^{2} \mathrm{M}^{\mathrm{COOPER}},{ }^{3} \mathrm{C}$ BRAUTBAR, ${ }^{4}$ AND A ASHKENAZI ${ }^{3}$
}

From Administration, ${ }^{1}$ Kaplan Hospital, Rehovot, Department of Medical Ecology, ${ }^{2}$ Hebrew UniveristyHadassah School of Public Health and Community Medicine, Jerusalem 91010, Department of Pediatrics, ${ }^{3}$ Kaplan Hospital, Rehovot, and Department of Immunology, ${ }^{4}$ Hebrew University-Hadassah Medical School, Jerusalem, Israel

SUMMARY The data from a large group of children with biopsy proved coeliac disease born in the Rehovot-Ashdod region of Israel and treated in a regional hospital provided us with the basis for the determination of the annual birth cohort incidence of coeliac disease for the period 1968-81. The findings show a minimum birth cohort incidence of $1 \cdot 71 / 1000$ live births. The highest incidence rate was in children of Asian origin and the lowest in second generation Israel born. The incidence of coeliac disease rose sharply during the study period.

The reported prevalence of coeliac disease varies considerably according to diagnostic methods used and the geographical region surveyed. Studies based on small bowel biopsy proved cases have found prevalence rates ranging from $1: 500$ to $1: 4500 .^{1-7}$

The goal of our study was to discover the incidence of coeliac disease in the Rehovot-Ashdod region of Israel, and to examine ethnic differences in the occurrence of the disease in this region.

Kaplan Hospital, a 520 bed acute care general hospital, serves a population of 250000 -the large west coast cities of Rehovot and Ashdod (50 00060000 each) and several smaller cities, towns and agricultural settlements spread over an area of about $1000 \mathrm{sq} \mathrm{km}$. Rehovot was settled in 1890 by refugees from Eastern Europe and Ashdod in 1956 by refugees from North African countries. Successive waves of immigration to the region have resulted in a population that today is about $65 \%$ North African, Asian, or Middle Eastern and 35\% Western in origin

Kaplan Hospital is owned by Kupat Holim, the Health Insurance Institute of the General Federation of Labor, and is a major teaching affiliate of the Hebrew University-Hadassah Medical School. There are 80 paediatric beds and a paediatric gastroenterology clinic directed by a full time paediatric gastroenterologist (AA).

\section{Patients and methods}

All patients were diagnosed by small intestinal biopsy. Morphological findings were classified as follows: 1 -normal, 2 -slight changes, 3 -partial villous atrophy, 4 subtotal villous atrophy, 5total villous atrophy. Findings 3-5 were considered diagnostic for coeliac disease.

Cases of coeliac disease were divided into three groups according to the number of biopsies performed as of 31 December 1982.

Group 1 included all patients with one pathological biopsy on a normal gluten containing diet.

Group 2 consisted of all patients with a pathological biopsy on normal diet and a second biopsy showing definite improvement on gluten free diet.

Group 3 included patients with a third biopsy showing deterioration of the mucosal appearance after gluten challenge. This group corresponds to the definition of ESPGAN, the European Society for Paediatric Gastroenterology. ${ }^{8}$

The total number of annual live births was obtained from the computerised records of Kaplan Hospital. Birth cohort incidence rates were calculated as the ratio of cases diagnosed among children born in a particular year per number of live births in that year. We tried to eliminate outmigrant patient bias by checking the records of the four major paediatric gastroenterological clinics in Israel, looking for any coeliac child born in our area but diagnosed outside our hospital. We found only one case and included him in our study. We also surveyed 10 paediatricians in the community, looking for patients with coeliac disease under their care. All 
cases of coeliac disease being treated by community paediatricians were known to us and had already been included in our study.

Ethnic origin of the mothers of the coeliac patients was assessed from the hospital records, and denominator data on ethnic origin of all parturient women was estimated from hospital records for the years 1970, 1973-6, and 1979-80. Ethnic specific rates were calculated and differences compared by the $z$ test.

Eighty four patients were screened by a method previously described ${ }^{\boldsymbol{\theta}}$ for the presence of HLA antigens B8, DRW3, and DRW7. The presence of these antigens was measured in the coeliac patients and a group of 90 adult controls, employees aged 20-35 of the Hebrew University-Hadassah Medical School. Half the controls were women, 52 (58\%) were of Western origin and 38 (42\%) were of Middle Eastern, Asian, or North African origin. Differences between coeliac patients and controls were compared by the $\mathrm{z}$ test.

\section{Results}

A total of 111 patients was diagnosed. Fifty eight (52\%) were female; seventy eight $(70 \%)$ were diagnosed by first biopsy before the age of 2 years. As of 31 December 1982, 37 of the 111 had fulfilled the classical definition of coeliac disease (group 3), and 67 had had two definitive biopsies - a pathological biopsy on a normal diet and a biopsy showing improvement on a gluten free diet (group 2).

The birth cohort incidence rate of coeliac disease, according to the ESPGAN definition, (group 3), was $0 \cdot 57 / 1000$ live births. For group 2 (diagnosis by two biopsies) and group 1 (one biopsy) the rates were 1.03 and 1.71/1000 live births, respectively (table 1 ). The smaller number of patients in groups 2 and 3 after the year 1975 reflected our policy of delaying the second and third biopsies for two to four years in most children who remain clinically well on the gluten free diet.

Since $80 \%$ of patients with a single positive biopsy who underwent second and third biopsies ultimately fulfilled the ESPGAN definition for coeliac disease, we thought that the incidence for group 1 was closest to the true incidence of coeliac disease, and subsequently we shall refer to group 1 as our incidence cases. The figure shows the annual birth cohort incidence rates in our population for the period 1969-79 (three year moving averages). There was an almost continuous rise in incidence from 1970 to 1978.

\section{ORIGIN}

Table 2 shows the distribution of the patients according to mother's country of birth and gives
Table 1 Live births and number of coeliac patients born in 1968-81 according to birth year and patient group*

\begin{tabular}{lcccc}
\hline Birth year & Group 1† & Group 2‡ & Group 3 & No live births \\
\hline 1968 & 6 & 4 & 2 & 4181 \\
1969 & 1 & 1 & 1 & 4246 \\
1970 & 3 & 2 & 1 & 4486 \\
1971 & 1 & - & - & 4723 \\
1972 & 3 & 3 & 3 & 4679 \\
1973 & 6 & 5 & 5 & 4177 \\
1974 & 7 & 6 & 4 & 4227 \\
1975 & 15 & 10 & 7 & 4551 \\
1976 & 9 & 9 & 4 & 4951 \\
1977 & 11 & 9 & 4 & 4930 \\
1978 & 11 & 9 & 3 & 4914 \\
1979 & 29 & 9 & 3 & 5038 \\
1980 & 6 & - & - & 4842 \\
1981 & 3 & - & - & 65000 \\
Total & 11 & 67 & 37 & \\
Average annual & & & & \\
incidence per & $1 \cdot 71$ & 1.03 & 0.57 & \\
1000 & & & & \\
\hline
\end{tabular}

* See methods for definition of three patient groups.

†Includes groups 2 and 3.

‡Includes group 3.

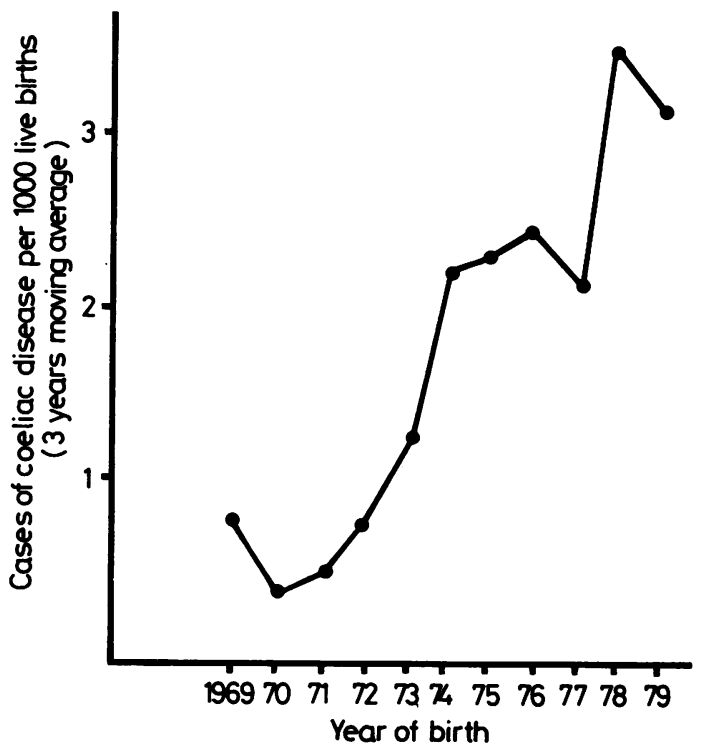

Birth cohort incidence of coeliac disease (group 1 cases, see methods).

Table 2 Coelic disease incıdence rates (per 1000 live births) according to mothers' origin, 1968-81.

\begin{tabular}{lcll}
\hline Mothers' origin & Live births & $\begin{array}{l}\text { Cases of } \\
\text { coeliac disease }\end{array}$ & $\begin{array}{l}\text { Birth cohort incidence } \\
\text { per 1000 live births }\end{array}$ \\
\hline $\begin{array}{l}\text { Asia and } \\
\text { Middle East }\end{array}$ & 9557 & 23 & 2.41 \\
N Africa & 13571 & 24 & 1.76 \\
$\begin{array}{l}\text { Europe and } \\
\text { Americas }\end{array}$ & 11277 & 20 & 1.77 \\
Israel & 29308 & 37 & 1.26 \\
Unknown & 1287 & 7 & - \\
\hline
\end{tabular}


origin specific incidence rates. The highest incidence was in children born to women of Asian and Middle Eastern origin and the lowest in children born to women born in Israel.

H LA

Eighty four patients were screened for presence of HLA B8, DRW3, and DRW7 and compared with a control group of 90 healthy controls. The three antigens were significantly more frequent in the cases than in the controls (table 3).

Table $3 H L A$ antigens in coeliac patients and controls

\begin{tabular}{|c|c|c|c|c|c|c|c|c|c|}
\hline \multirow[b]{2}{*}{ Antigen } & \multicolumn{2}{|c|}{$\begin{array}{l}\text { Group 1 } \\
(n=84)\end{array}$} & \multicolumn{2}{|c|}{$\begin{array}{l}\text { Group } 2 \\
(n=49)\end{array}$} & \multicolumn{2}{|c|}{$\begin{array}{l}\text { Group } 3 \\
(n=34)\end{array}$} & \multicolumn{2}{|c|}{$\begin{array}{l}\text { Controls } \\
(n=90)\end{array}$} & \multirow[b]{2}{*}{$p^{*}$} \\
\hline & No & $\%$ & No & $\%$ & No & $\%$ & No & $\%$ & \\
\hline B8 & 21 & $25 \cdot 0$ & 12 & 24.5 & 8 & 23.5 & 6 & $6 \cdot 7$ & 0.0008 \\
\hline DRW3 & 32 & $38 \cdot 1$ & 19 & $38 \cdot 8$ & 13 & $38 \cdot 2$ & 13 & 14.4 & 0.0003 \\
\hline DRW7 & 39 & 46.4 & 23 & 46.9 & 17 & 50.0 & 22 & 24.4 & 0.002 \\
\hline
\end{tabular}

*For difference between group 1 and controls.

\section{Discussion}

We have indicated our reasons for believing that our group 1 incidence rate is close to the true incidence rate of coeliac disease. Additonal evidence is the almost identical HLA distribution of groups 1,2, and 3 (table 3 ). Using our average rate of $1 \cdot 71 / 1000$, our incidence is higher than that of Scotland, Switzerland, and France,,$^{58}$ the same as Ireland, ${ }^{2}$ and lower than Austria. ${ }^{3}$

It is possible, furthermore, that we have underestimated the true incidence of coeliac disease in our population because of the presence of subclinical cases, late diagnosis in adults, and the possibility that some infants died before diagnosis could be made.

The clear rise in the incidence rate during the period 1970-8 corresponds with the results of Jansson $^{6}$ and Borgfors ${ }^{10}$ from Sweden. We do not think that the rise is an artifact of increased awareness of the disease, particularly since we have presented birth cohort incidence rates, and any increased suspicion of the diagnosis in the later years of the survey would have added more cases to earlier birth cohorts as well as to later ones.

The downward turn of the incidence curve in the birth year 1979 may, however, be an artifact of not yet diagnosed cases. If future surveys show a continued fall in incidence, as noted by Littlewood, ${ }^{11}$ then the persistent intermarriage of Jews of different ethnic origins (and genetic backgrounds) will undoubtedly be invoked as an explanation of the decrease. ${ }^{12}$ It is too early, however, to say with any certainty that the disease is on the wane.

We have shown different incidence rates in our different ethnic origin groups. There are numerous reports of differing incidence of coeliac disease in different ethnic groups in other countries, ${ }^{4613}$ but as in the other studies it has not been possible for us to distinguish between genetic and dietary influences. In all likelihood both play a part in establishing susceptibility and influencing the clinical picture of this disease.

Supported in part by Stifftung Volkswagenwerk, Federal Republic of Germany.

\section{References}

${ }^{1}$ Berg NO, Lindberg $T$. Incidence of coeliac disease and transient gluten intolerance in children in a Swedish urban community. Acta Paediatr Scand 1979; 68: 397401.

${ }^{2}$ Mylotte M, Egan Mitchell B, McCarthy CF, McNicholl B. Incidence of coeliac disease in the west of Ireland. $\mathrm{Br}$ Med J 1973; i: 703-5.

${ }^{3}$ Rossipal E. Haufigkeit der Coliakie im Einzugsgebeit de KinderKlinik Graz. Zeitschrift fur Kinderheilkunde 1975; 119: 143-9.

${ }^{4}$ Ferguson A, Lai CL, Denton-Miller P. Coeliac diseaseobjectives of life-long follow-up. Health Bull (Edin) 1977; 35: 78-80.

${ }^{5}$ Bernier JJ, Bourdeloux JJ. Frequence de la maladie coeliaque. Arch Franc Mal Appar Dig 1974; 63: 361-4.

${ }^{6} \mathrm{Jansson} \mathrm{G}$. Stenhammer L. Incidence of coeliac disease in children in a Swedish county. Opuscula Medica 1981; 26: 67-8.

${ }^{7}$ Shmerling DH, Leisinger P, Prader A. On the familial occurrence of coeliac disease. Acta Paediatr Scand 1972; 61: 501 .

${ }^{8}$ Meeuwisse GW. Diagnostic criteria in coeliac disease. Acta Paediatr Scand 1970; 59: 461-3.

${ }^{9}$ Brautbar C, Freier S, Ashkenazi A. Histocompatibility determinants in Israeli Jewish patients with celiac disease: population and family study. Tissue Antigens 1981; 17: 313-22.

${ }^{10}$ Borgfors $\mathrm{N}$, Selander $\mathrm{P}$. The incidence of coeliac disease in Sweden. Acta Paediatr Scand 1968; 57: 260.

${ }^{11}$ Littlewood JM, Crollick HA, Richards IDG. Childhood coeliac disease is disappearing. Lancet 1980; ii: 1359.

${ }^{12}$ Davies AM. Migrants and their children in Israelidentification and changes. Isr J Med Sci 1971; 7: 13427.

${ }^{13}$ Sheldon W. Coeliac disease. Lancet 1955; ii: 1097-1103. 